\title{
LOYALITAS PELANGGAN MELALUI PROGRAM SUBSIDI, COMPLAINT HANDLING DAN CITRA MEREK KORAN KOMPAS PADA PT. POLAMEDIA CIPTA NUSANTARA CABANG SOLO
}

\author{
Rinta Nurcahyati, Bambang Mursito, Eny Kustiyah \\ Program Studi Manajemen Fakultas Ekonomi Universitas Islam Batik Surkarta \\ Jl. KH. Agus Salim No. 10, Telp. 0271-714751 Surakarta \\ E-mail : rintanurcahyati2109@gmail.com
}

\begin{abstract}
This study aims to determine customer loyalty through the subsidy program, complaint handling, and the image of Kompas Newspapers in PT Polamedia Cipta Nusantara. The dependent variable (Y) in this study is customer loyalty. Independent variable (X1) Subsidy program, (X2) Complaint handling, and (X3) Brand image. Methods of data analysis using multiple linear regression. This study used a sample of 100 respondents using simple random sampling techniques. Collecting data using a questionnaire that has passed the validity and reliability test Whereas for data programs using IBM SPSS 21.0 statistics. The analysis shows that there is a simultaneous and probability influence of the subsidy program variables, complaint handling and brand image on customer loyalty.
\end{abstract}

Keyword: customer loyalty, subsidy programs, complaint handling, brand image

\section{PENDAhuluan}

Suatu rangkaian yang dinamis merupakan kegiatan pemasaran yang terjadi tidak secara kebetulan tetapi dapat melalui proses tertentu diawali dengan adanya berbagai perubahan yang dikendali, baik dalam tingkat perekonomian, sosial pasar dan teknologi. Perusahaan manufaktur telah menyadari pentingnya jasa sebagai bentuk peningkatan keunggulan di kompetitif bisnisnya. Kelangsungan hidup perusahaan sangat ditentukan dengan kualitas pelayanan yang sangat baik. Pelanggan akan loyal dan terus menggunakan layanan jasa tersebut jika yang didapatkan layanan yang baik, mendorong terciptanya loyalitas pelanggan dapat mempengaruhi terciptanya tingkat kepuasan kepada pelanggan (Ramenusa, 2013). Kelangsungan hidup organisasi atau perusahaan tergantung konsumen, konsumen loyal atau konsumen yang melakukan pembelian berulang sangat dapat diandalkan.

Loyalitas konsumen sangat penting, dipengaruhi dengan promosi-promosi, harga yang terjangkau dan memberikan kepuasan kepada pelanggan menjadi faktor yang sangat mempengaruhi loyalitas konsumen (Anggia, Kawet \& Ogi, 2015). Pelanggan loyal dan dapat diandalkan pasti yang sudah merasakan akan kualitas produk dan jasa yang dibeli dari perusahaan tertentu.

Dalam era persaingan bisnis, perusahaan harus memperhatikan faktor-faktor kebutuhan pelanggan, hal yang membuat atau sangat mempengaruhi kemampuan bersaing di dalam bidang bisnis besar kecilnya suatu harga sangat mempengaruhi pelanggan untuk membeli produk 
tertentu. Potongan harga (discount) atau di penelitian ini disebut dengan Program subsidi, memberikan potongan harga dari harga yang sebelumnya sudah ditetapkan.

Pemberian diskon atau potongan harga dapat digunakan dalam bentuk strategi untuk menarik perhatian pelanggan, lebih cepat dan sangat efektif (Prabarini, Heryanto \& Astuti, 2018). Tujuan memberikan potongan harga kepada pelanggan selain meningkatkan jumlah penjualan, dan untuk mendorong minat baca pelanggan dalam jumlah besar.

Umpan balik dari kualitas produk dan jasa yang diberikan dapat dilihat dalam bentuk keluhan pelanggan. Ketika harapan layanan tidak terpenuhi kesenjangan yang dihasilkan mengarah ke ketidakpuasan tetapi ketika harapan dilampaui, hasilnya adalah kepuasan yang sangat mempengarhi loyalitas pelanggan (Holloway \& Beatty, 2017).

Menciptakan pelanggan dengan adanya pemasaran yang baik didalam persaingan bisnis pemasaran merupakan tujuan perusahaan dalam membangun keputusan pelanggan dalam memutuskan pembelian suatu produk tertendu. Mencari informasi sebelum membeli barang atau produk yang dibutuhkan, teliti dalam kualitas yang dimiliki produk sebelum membeli merupakan dampak dari berkembangnya dunia teknologi yang sangat canggih dan dampak terhadap pola loyalitas pelanggan saat ini. Citra merek dan kredibilitas yang baik di suatu produk akan dicari oleh calon-calon pembeli berdasarkan informasi yang biasanya diperoleh dari kerabat dekat (Rahmadi, 2017). Sebuah perusahaan memiliki fitur, layanan dan manfaat untuk para pelanggan digambarkan dalam sebuah merek itu sendiri.

\section{LANDASAN TEORI}

\section{Program Subsidi}

Program Subsidi atau Potongan harga (discount) merupakan strategi yang dilakukan perusahaan dengan memebrikan potongan harga dari harga yang sudah ditetapkan sebelumnya. Sebuah alat atau strategi dalam pemsarann yang bermanfaat yaitu dengan memberikan sebuah potongan harga untuk produk yang akan dibeli oleh pelanggan. Menurut Soemarso (2002: 162) Dengan memenuhi syarat yang berlaku dengan cara pembayaran dilakukan lebih cepat dari waktu yang ditetapkan dengan mendapatkan Potongan harga (Cash).

\section{Complaint Handling}

Complaint handling atau sebuah keluhan dari pelanggan bisa disampaikan dengan ketidak puasan pelanggan menerima produk atau jasa yang telah diberikan. Menurut Iyola \& Ibidunni (2013) Perilaku Keluhan konsumen dapat diklasifikasikan menjadi tiga kategori yang mungkin respons suara, respons pribadi, dan respons pihak ketiga.

\section{Citra Merek}

Loyalitas konsumen itu sebuah gambaran dari suatu merek dalam sifat yang sangat baik dalam pembelian produk dan jasa dalam jangka waktu yang sangat panjang (Tjiptono, 2004: 110). Suatu kesetiaan terhahadap merek yang dapat dilihat dan dirasakan dari keluhan dan kepuasan pelanggan. Citra merek sangat memberi pengaruh besar terhadap kepuasan pelanggan yang dapat diperoleh dengan banyak menimbulkan kepuasaan para pelanggan dan mengurangi keluhan para pelanggan dengan begitu akan banyak memperoleh pembelian dalam waktu yang berkepanjangan. 


\section{METODE PENELITIAN}

Metode penelitian ini menggunakan penelitian kuantitatif deskriptif. Teknik analisis data menggunakan analisis statistik dan menjelaskan serta memberi gambaran tentang objek yang diteliti dan melalui data sampel yang sudah dikumpulkan. Waktu yang digunakan oleh peneliti dalam melakukan penelitian ini dari bulan Agustus 2019 sampai Januari 2020. Sedangkan sample adalah semua pelanggan Koran kompas di PT Polamedia Cipta Nusantara Cabang Solo Sebanyak 100 Responden. Alat yang digunakan analisisa data dalam panelitian ini uji asumsi klasik, regresi linier berganda dan uji hipotesa.

\section{HASIL PENELITIAN DAN PEMBAHASAN}

\section{Uji Koefisien Determinan $\left(\mathbf{R}^{2}\right)$}

Hasil analisa data menggunakan aplikasi SPSS versi 21 diperoleh nilai $\mathrm{R}^{2}$ sebesar0,438 atau43,8\%, nilai ini membuktikan program subsidi, complaint handling, dan citra merek mempengaruhi variabel loyalitas pelanggan sebesar $43,8 \%$. Sisanya $56,2 \%$ dijelaskan variabel lain yang tidak ada di penelitian ini.

\section{Regresi Linier Berganda}

Hasil analisa data ini menggunakan aplikasi SPSS versi 21 di peroleh hasil uji Regresi Linier Berganda sebagai berikut :

$$
\mathrm{Y}-4,907+0,148 \mathrm{X}_{1}+0,227 \mathrm{X}_{2}+0,415 \mathrm{X}_{3}+\mathrm{e}
$$

Nilai konstanta sebesar 4,907 menunjukkan bahwa apabila program subsidi, complaint handling, dan citra merek nilainya 0 , maka loyalitas pelanggan akan berada pada 4,907 satuan.

Nilai koefisien program subsidi menunjukkan 0,148 .

Maka dapat dijelaskan apabila program subsidi meningkat, loyalitas pelanggan dapat meningkat sejumlah 0,148 satuan.

Nilai koefisien complaint handling menunjukkan 0,227. Maka dapat dijelaskan apabila complaint handling meningkat, loyalitas pelanggan dapat meningkat sejumlah 0,227 satuan.

Nilai koefisien citra merek menunjukkan 0,415. Maka dapat dijelaskan apabila citra merek meningkat, loyalitas pelanggan dapat meningkat sejumlah 0,415 satuan.

\section{Uji Asumsi Klasik}

\section{Uji Normalitas}

Peneliti menggunakan kolmogorov-smirnov dalam uji normalitas ini, hasil sebagai berikut :

Tabel I. Hasil Uji Normalitas Kolmogorov Smirnov

\begin{tabular}{|c|c|c|c|}
\hline Kolmogorov -Smirnov Z & Signifikansi & Batas & Keterangan \\
\hline 0,432 & 0,992 & 0,05 & Normal \\
\hline Sumber: DataPrimer diolah tahun 2019
\end{tabular}


Hasil pengujian diatas membuktikan nilai (K-S)Z sebanyak 0,432 dan signifikan pada 0,992 lebih dari 0,05, dinyatakan data yang diteliti pembagian normal.

\section{Uji Multikolinearitas}

Peneliti menggunakan teknik tolerance (TOL)dan variance inflation factors (VIF) untuk uji multikolinearitas, dengan hasil sebagai berikut :

Tabel II. Hasil Uji Multikolineritas

\begin{tabular}{|l|c|c|c|}
\hline \multicolumn{1}{|c|}{ Variabel } & Tolerance & VIF & Keterangan \\
\hline Program Subsidi & 0,531 & 1,882 & Tidak terjadi multikolineritas \\
\hline Complaint Handling & 0,577 & 1,732 & Tidak terjadi multikolineritas \\
\hline Citra Merek & 0,519 & 1,927 & Tidak terjadi multikolineritas \\
\hline
\end{tabular}

Hasil pegujian ini menunjukkan bahwa nilai TOL diatas 0,10 danVIF dibawah 10, dapat dinyatakan persamaan regresi tidak terjadiadanya multikolinearitas.

\section{Uji Heteroskedastisitas}

Peneliti menggunakan metode glejser untuk uji heteroskedastisitas, dengan hasil sebagai berikut :

Tabel III. Hasil Uji Heteroskedastisitas Glejser
\begin{tabular}{|l|c|c|c|}
\hline \multicolumn{1}{|c|}{ Variabel } & Signifikansi & Batas & Keterangan \\
\hline Program Subsidi & 0,663 & $>0,05$ & Tidak terjadi heteroskedastisitas \\
\hline Complaint Handling & 0,058 & $>0,05$ & Tidak terjadi heteroskedastisitas \\
\hline Citra Merek & 0,742 & $>0,05$ & Tidak terjadi heteroskedastisitas \\
\hline
\end{tabular}
Sumber: Data Primer diolah tahun 2019

Hasil pengujian ini menunjukkan nilai probabilitas lebih tinggi dari 0,05. Dapat di katakan bahwa semua variabel independen tidak terdapat adanya heteroskedastisitas.

\section{Analisis Data}

\section{Uji F}

Berdasarkan data yang diolah dengan aplikasi SPSS 21 didapat nilai signifikansi $\mathrm{F}$ hitung sebesar 26,738 lebih dari $\mathrm{F}$ tabel 2,70 dan taraf signifikan 0,000 kurang dari 0,05. Maka dijelaskan bahwa program subsidi, complaint handling dan citra merek secara simultan dan probabilitas dapat mempengaruhi loyalitas pelanggan Koran kompas di PT Polamedia Cipta Nusantara Cabang Solo. 


\section{Uji t}

Berdasarkan data yang diolah dengan aplikasi SPSS 21variabel Program subsidi tidak terdapat pengaruh dan tidak signifikan secara parsial pada loyalitas pelanggan Koran kompas di PT Polamedia Cipta Nusantara Cabang Solo yang ditunjukkan dengan nilai $t_{\text {hitung }}$ sebesar 1,666 kurang dari $t_{\text {tabel }} 1,984$. Variabel citra merek terdapat pengaruh dan probabilitas secara parsial terhadap loyalitas pelanggan Koran kompas di PT Polamedia Cipta Nusantara Cabang Solo dengan nilai $t_{\text {hitung }}$ sebanyak 2,477 lebih dari $t_{\text {tabel }}$ 1,984. Variabel citra merek terdapat pengaruh dan signifikan secara parsial terhadap loyalitas pelanggan Koran kompas di PT Polamedia Cipta Nusantara Cabang Solo. Sejalan dengan dengan penelitian Ramenusa (2013).

\section{Pembahasan}

\section{Pengaruh Variabel Program Subsidi terhadap Loyalitas Pelanggan}

Hasil perhitungan uji t untuk variabel Program subsidi secara parsial berpengaruh negatif dan probabilitas pada loyalitas pelanggan. Terdapat dari nilai $t_{\text {hitung }}$ sebanyak 1,666 pada tingkat probabilitasnya sebesar 0,099 , koefisien regresi mempunyai nialisebesar 0,148 dan probabilitasnya kurang dari $5 \%>0,000$ berrarti $<0,05$ maka $\mathrm{H}_{\mathrm{o}}$ di tolak, terdapat pengaruh probabilitasnya pada loyalitas pelanggan. Membuktikan kenaikan program subsidi tidak menjadikan meningkatnya loyalitas pelanggan. Seperti pada persyaratan untuk mendaptkan harga khusus dalam program subsidi sehingga tidak semua pelanggan bisa memenuhi syaratsyarat atau kriteria agar mendapatkan harga khusus program subsidi dalam berlanggan Koran kompas. Ini tidak sejalan terhadap penelitian yang telah dilakukan oleh Anggia et all. (2015). Menyatakan bahwa memberikan potongan harga dapat mempengaruhi tingkat loyalitas pelanggan serta mendorong jumlah ditawarkan besar.

\section{Pengaruh Variabel Complaint Handling terhadap Loyalitas Pelanggan}

Berdasarkan hasil uji t diperoleh bahwa variabel Complaint Handling secara sebagian berpengaruh negatif dan probabilitas pada loyalitas pelanggan koran kompas pada PT Polamedia Cipta Nusantara Cabang Solo. Didapat dari hasil $t_{\text {hitung }}$ sebesar 2,477, koefisien regresi mempunyai nilai sebesar 0,227 dan signifikansi sebesar $<5 \%$ yaitu 0,015 berarti berarti kurang dari 0,05 maka $\mathrm{H}_{\mathrm{o}}$ di tolak, maka diperoleh pengaruh probabilitas pada loyalitas pelanggan. Ini sejalan dengan penelitian Indrayani \& Mardiana (2016) Complaint handling merupakan suatu peluang untuk memperkuat loyalitas pelanggan.

\section{Pengaruh Variabel Citra Merek terhadap Loyalitas Pelanggan}

Berdasarkan hasil uji t diperoleh bahwa variabel Citra merek $\left(\mathrm{X}_{3}\right)$ secara parsial berpengaruh negatif dan signifikan terhadap loyalitas pelanggan koran kompas pada PT Polamedia Cipta Nusantara Cabang Solo. Didapat dari hasil $t_{\text {hitung }}$ sebesar 3,462, koefisien regresinya memiliki nilai sebesar 0.415 dan signifikasinya kurang dari $5 \%$ yaitu 0,001 berarrti lebih kecil dari 0,05 maka $\mathrm{H}_{\mathrm{o}}$ di tolak, diperoleh pengaruh probabilitas pada loyalitas pelanggan. Menunjukan kenaikan citra merek mempengaruhi meningkatnya loyalitas pelanggan koran kompas pada PT Polamedia Cipta Nusantara Cabang Solo. Ini sejalan dengan penelitian Januar (2016) Kepercayaan merek bagi pelanggan akan berdampak terhadap kesetiaan dan loyalitas 
pelanggan. Citra merek sangatlah penting untuk sebuah produk itu sendiri, produk yang memilki kesamaan tidak tentu mempunyai citra yang sama juga dihadapan orang lain. Menjadi salah satu peganggan pelanggan terus meningkatkan loyalitas berlangganan koran kompas berdasarkan citra merek yang dimiliki.

\section{KESIMPULAN}

Dari hasil penelitian dengan judul maka dapat disimpulkan, Program Subsidi, Complaint Handling Dan Citra Merek secara simultan dan probabilitas berpengaruh terhadap loyalitas pelanggan Koran kompas pada PT Polamedia Cipta Nusantara Cabang Solo. Hasil ini dibuktikan

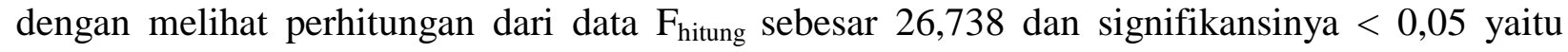
0,000 .

\section{DAFTAR PUSTAKA}

Anggia, Riry Tulandi et.all. 2015. Analisis Pengaruh Strategi Promosi, Harga, Dan Kepuasan Terhadap Loyalitas Konsumen Surat Kabar Manado Post. Jurnal EMBA, vol. 3, No. 2, Hal.1041-1050.

Fandy, Tjiptono. 2004. Strategi Pemasaran, Edisi Kedua. Andi. Yogyakarta.

Indriyani, Susi dan Selvy Mardiana. 2016. Pengaruh Penanganan Keluhan (Complaint Handling) terhadap kepercayaan dan komitmen Mahasiswa Pada Perguruan Tinggi Swasta di Bandar Lampung. Jurnal Bisnis Darmajaya, Vol . 2, No. 01

Iyiola and Ibidunni. 2013. The Relationship between Complaints, Emotion, Anger, and Subsequent Behavior of Customers. IOSR Journal Of Humanities And Social Science (IOSR-JHSS), Vol. 17, Issued. 6, pp. 3441.

Januar, Al fajri. 2016. Pengaruh Citra Merek Dan Kepercayaan Merek Terhadap Loyalitas Konsumen (studi kasus pada koran harian pt. Riau pos intermedia). JOM FISIP Vol. 3, No. 2.

Prabani, Anggun, Heryanto, Astuti. 2018. Pengaruh Promosi Penjualan dan Potongan Harga Terhadap Keputusan Pembelian Konsumen Produk kecantikan Wardah Di Toserba Borobudur Kediri. JIMEK. Vol, 1. No. 2 Desember 2018.

Rahmadi. 2017. Pengaruh Citra Merek dan Kualitas Produk Terhadap Loyalitas Pelanggan Salbutamol Nebules. Jurnal Monex, Vol. 6. No. 2. Juni 2017.

Ramenusa, Oktaviani. 2013. Kualitas Layanan dan Kepuasan Pelanggan Pengaruhnya Terhadap Loyalitas Pelanggan Pada PT. DGS Manado. Jurnal EMBA, Vol. 1, No. 3, Hal. 11931202.

Soemarso. 2002. Akuntansi Statu Pengantar. Buku 1. Edisi Lima. Jakarta: Salemba Empat. 